\title{
Gating system optimization of high pressure die casting thin-wall AISi10 MnMg longitudinal load- bearing beam based on numerical simulation
}

\author{
Xu Zhao, * Ping Wang, Tao Li, Bo-yu Zhang, Peng Wang, Guan-zhou Wang, and Shi-qi Lu \\ Key Laboratory of Electromagnetic Processing of Materials, Northeastern University, Shenyang 110000, China.
}

\begin{abstract}
High pressure die casting (HPDC) is a kind of near net shape manufacturing method. However, air entrapment in HPDC parts has serious effects upon the casting quality. In order to reduce the air entrapment defects in a AISi10MnMg alloy thin-wall longitudinal load-bearing beam produced by HPDC, different gating systems were designed and simulated by software Flow-3D to evaluate the entrapped air. Simulation results showed that when the beam is produced by the original designed gating system with a middle ingate, there exist obvious air entrapments in the critical area; the volume of air entrapment was reduced by replacing the middle ingate to an overflow well, and the filling of molten metal became more stable. When the middle ingate was removed for further improvement, the volume of air entrapment was decreased drastically. The parts with glossy surface and good microstructure have been successfully produced by using the final optimized gating system based on simulation results.
\end{abstract}

Key words: AlSi10MnMg; high pressure die casting; gating system optimization; numerical simulation

CLC numbers: TG146.21 Document code: A

Article ID: 1672-6421(2018 06-436-07

$\mathrm{T}$ he use of thin-wall AlSi10MnMg high pressure die casting (HPDC) parts has grown considerably in past years and is still continuously rising in the automotive industry ${ }^{[1]}$. Due to lightweight necessity, the number of thin-wall AlSi10MnMg HPDC aluminum parts, such as suspension components, supporting parts and wheels, is rising with a lot of advantages due to good mechanical properties ${ }^{[2-3]}$.

High pressure die casting is a kind of near net shape manufacturing method of complex geometry parts in the automotive industry at relatively low production costs ${ }^{[4]}$. It is a very suitable way to produce thin-wall AlSi10MnMg supporting parts ${ }^{[5]}$. However, defects like air entrapment formed at the filling stage have influenced the quality and the application of thin-wall HPDC AlSil0MnMg parts due to the fact that the gas has not enough time to escape from the casting because of the irrationality of the gating system design. Therefore, a reasonable design for a gating system is one of the key factors to assure product quality during the production of

\section{*Ping Wang}

Male, born in 1964, Professor. His research mainly focuses on the preparation, processing, and semi-solid casting of $\mathrm{Cu}$ and $\mathrm{Al}$ alloys.

E-mail: wping@epm.neu.edu.cn

Received: 2018-04-18; Accepted: 2018-07-20

castings ${ }^{[6]}$.

At present, a flow and thermal modeling computer simulation software Flow-3D has been extensively used to analyze the filling processes of HPDC castings with different gating systems, and software ProE has also been used for modifying the gating system and die $\operatorname{design}^{[7]}$.

Longitudinal load-bearing beam is a thin-wall HPDC AlSi10MnMg structural part for a vehicle body. Excellent mechanical properties and dense microstructure are required. However, a number of air entrapments often appeared in the critical area of the parts during production. Although the filling velocity, melting temperature and die temperature had been adjusted, the air entrapment defect was not yet eliminated by optimizing casting parameters with the initial designed gating system. In order to decrease the occurrence of air entrapment defects during the filling process and improve the product quality, a HPDC gating system for the thin-wall longitudinal load-bearing beam structural part made of AlSi10MnMg alloy was modified and simulated, and the advantages and disadvantages of the different gating system designs were analyzed. Finally, the numerical simulation results were well testified by practical production verification and microstructure characterization analysis. 


\section{Simulation and optimization}

\subsection{Geometry modeling and defect description}

Figure 1 shows the 3D-model of the original thin-wall HPDC AlSi10MnMg longitudinal load-bearing beam with initial gating system using a comb-type design with seven ingates. The fringe of the part is $6 \mathrm{~mm}$ thickness and average thickness of the casting is $3 \mathrm{~mm}$, the height of the strengthening rids is $2 \mathrm{~mm}$ and the outline of the part is $250 \mathrm{~mm} \times 80 \mathrm{~mm} \times 6 \mathrm{~mm}$.

The material of the longitudinal load-bearing beam is
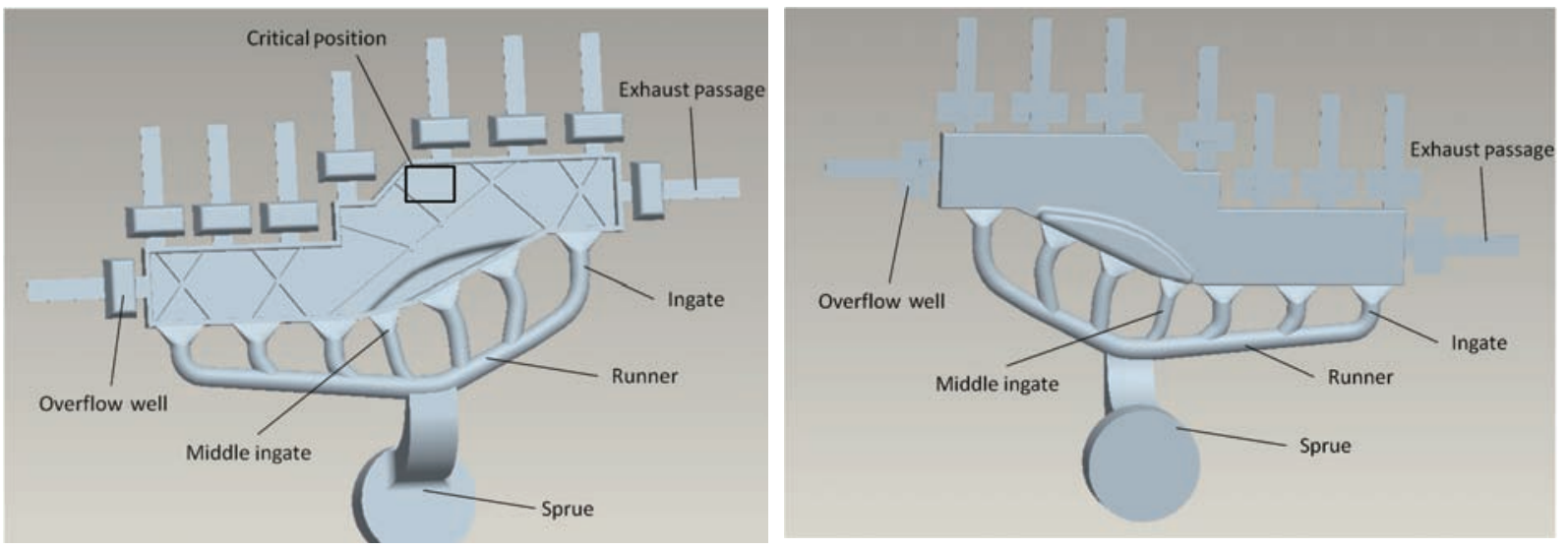

Fig. 1: 3D-Model of thin-wall AISi10MnMg HPDC longitudinal load-bearing beam and original gating system made by Pro-E

$\mathrm{AlSi}_{10} \mathrm{MnMg}$ alloy. Tables 1 and 2 show chemical compositions and material properties of AlSi10MnMg alloy, respectively. The HPDC die was made by H13-Steel. The numerical simulation on the filling processes of the longitudinal load-bearing beam was carried out with Flow-3D software. The step size of simulation was set as 0.0008 and the total number of the meshes was 16,945,929. Table 3 shows the initial and boundary conditions of simulation.

Table 1: Chemical composition of $\mathrm{AlSi}_{10} \mathrm{MnMg}$ longitudinal load-bearing beam (wt.\%)

\begin{tabular}{|c|c|c|c|c|c|c|c|c|c|}
\hline $\mathrm{Si}$ & Mg & Mn & $\mathrm{Fe}$ & $\mathrm{Mn} / \mathrm{Fe}$ & $\mathrm{Ti}$ & $\mathrm{Sr}$ & $\mathrm{Zn}$ & $\mathrm{Cu}$ & Al \\
\hline 10.57 & 0.361 & 0.526 & 0.228 & 2.31 & 0.0618 & 0.0144 & 0.000930 & 0.00189 & 88.2 \\
\hline
\end{tabular}

Table 2: Material parameters of AISi10MnMg alloy ${ }^{[5]}$

\begin{tabular}{|c|c|c|c|}
\hline $\begin{array}{l}\text { Density } \\
\mathbf{k g} \cdot \mathrm{m}^{-3}\end{array}$ & $\begin{array}{l}\text { Liquidus/solidus temperature } \\
\text { K }\end{array}$ & $\begin{array}{l}\text { Latent heat } \\
\quad \mathbf{k J} \cdot \mathbf{k g}^{-1}\end{array}$ & $\begin{array}{l}\text { Specific heat } \\
\mathbf{k J} \cdot \mathrm{kg}^{-1} \cdot \mathrm{K}^{-1}\end{array}$ \\
\hline 2472 & $897 / 825$ & 332 & 1245 \\
\hline
\end{tabular}

The melting of AlSi10MnMg ingots was conducted in a crucible preheated to 350 to $400{ }^{\circ} \mathrm{C}$. Before melting, AlSi10MnMg ingots were first preheated to $200^{\circ} \mathrm{C}$, then the ingots were placed into the crucible and the crucible was heated to $750{ }^{\circ} \mathrm{C}$ until the ingots were fully melted under the protection of high purity argon gas. Figure 2 shows the HPDC-produced longitudinal load-bearing beam using the casting process parameters shown in Table 4. The sampling position for metallographic observation was in the critical position, as shown in Fig. 2. Microstructure was observed on a Leica metallographic microscope.

The macro photos and X-ray test results of the critical area are shown in Fig. 3. It can be seen that obvious air entrapment defects occurred in the casting produced by the above-mentioned original gating system.
Table 3: Initial and boundary conditions for simulation

\begin{tabular}{ccccc} 
Temperature $\left({ }^{\circ} \mathrm{C}\right)$ & $\begin{array}{c}\text { Ingate filling } \\
\text { velocity } \\
\left(\mathbf{m} \cdot \mathbf{s}^{-1}\right)\end{array}$ & $\begin{array}{c}\text { Heat-transfer coefficient } \\
\left(\mathbf{W} \cdot \mathbf{m}^{-2} \cdot \mathbf{K}^{-1}\right)\end{array}$ \\
\hline Die & Melt & Metal & Solidified metal \\
\hline 220 & 650 & 2 & 1,000 & 2,000
\end{tabular}

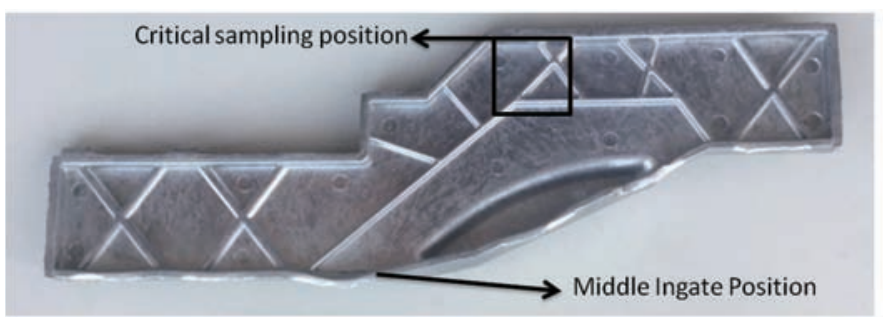

Fig. 2: Critical sampling position of X-ray test and microstructure observation 
Table 4: Process parameters of high pressure die casting

\begin{tabular}{|c|c|c|c|}
\hline $\begin{array}{c}\text { Slow jet velocity } \\
\left(m \cdot \mathbf{s}^{-1}\right)\end{array}$ & $\begin{array}{l}\text { Fast jet velocity } \\
\qquad\left(\mathrm{m} \cdot \mathrm{s}^{-1}\right)\end{array}$ & $\begin{array}{l}\text { Melting temperature } \\
\left({ }^{\circ} \mathrm{C}\right)\end{array}$ & $\begin{array}{c}\text { Die temperature } \\
\left({ }^{\circ} \mathrm{C}\right)\end{array}$ \\
\hline 0.3 & 2.0 & 650 & $200-250$ \\
\hline
\end{tabular}
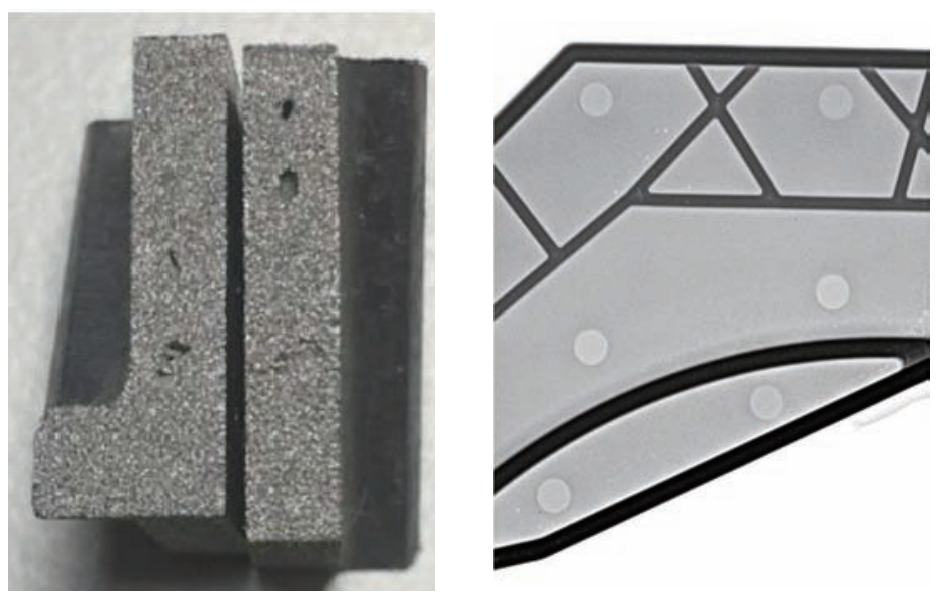

Fig. 3: Photos and X-ray test results of air entrapment defects based on original gating system
Figure 4 shows the metallographic photos at the critical area of the beam part produced by the original gating system. It can be observed that there are serious air entrapments in the part. The low magnification metallography [Fig. 4(a)] shows an obvious macro air entrapment defect and the high magnification metallography [Fig. 4(b) and 4(c)] shows a certain amount of small-sized entrapped air. Table 5 shows the mechanical properties of the part produced by the original gating system. It is evident that the tested values are lower than the properties requirements of the beam.
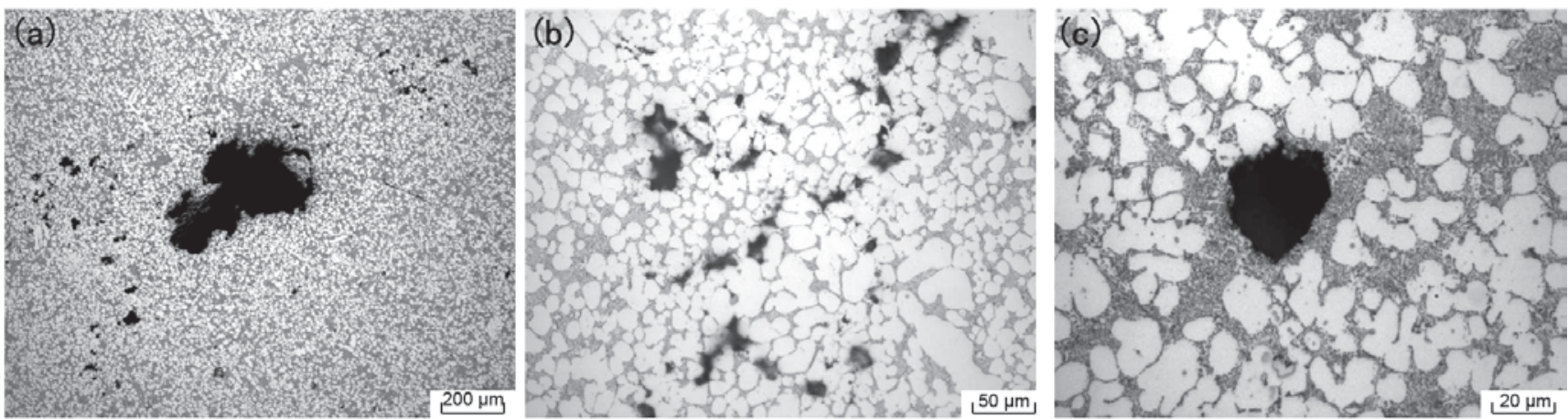

Fig. 4: Critical area metallographic photos based on original gating system with different magnifications

Table 5: Mechanical properties of longitudinal load-bearing beam produced by original gating system

$\begin{array}{cccc} & \boldsymbol{R}_{\mathrm{p} 0.2}(\mathrm{MPa}) & \boldsymbol{R}_{\mathrm{m}}(\mathrm{MPa}) & \boldsymbol{A}(\%) \\ \begin{array}{c}\text { Properties } \\ \text { requirements }\end{array} & 145.00 & 185.00 & 2.000 \\ \begin{array}{c}\text { Test } \\ \text { properties }\end{array} & 140.79 & 168.32 & 1.695\end{array}$

\subsection{Simulation results with original gating system}

The simulation results of filling processes of the longitudinal load-bearing beam with original gating system are shown in Fig. 5. It can be seen that the middle ingate is filled firstly by molten metal [shown in Fig. 5(a)]. The filling process is not smooth, and the liquid injecting from the middle ingate has an obvious confluence. The fluid has more contact with air at $0.020 \mathrm{~s}$ in Fig. 5(b). Under the circumstance, the gas is easily drawn into the molten metal and results in air entrapment defects. As shown in Fig. 5(c), when the filling time is $0.028 \mathrm{~s}$, the mold cavity is fully filled, and there exist a number of air entrapments in the left and the top of the longitudinal loadbearing beam castings. Figure 5(d) shows the simulation result of the end of the filling process. As it can be seen, there is a large area with air entrapment defects in the mold cavity, especially in the left and the top of longitudinal loadbearing beam. Serious fluid convection happens because of the unsynchronized filling sequence from different ingates. If the volume of air entrapment cannot be decreased, it will be difficult to produce a sound casting. Therefore, the gating system must be optimized.

\subsection{Simulation results with optimized gating system}

In order to decrease the frequency of confluence caused by overmuch ingates and make the filling process more stable, the initial gating system of the longitudinal load-bearing beam was optimized, as shown in Fig. 6. The middle ingate was replaced by an overflow well due to its priority of filling. Figure 7 shows the filling process simulation results with the optimized gating 
(a)

Time $=0.01808 \mathrm{~s}$

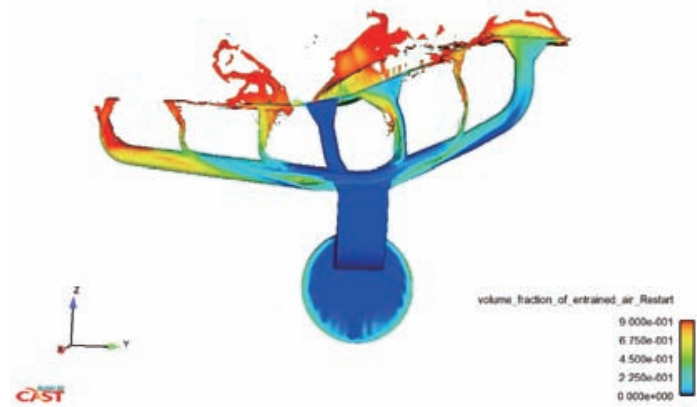

(c)

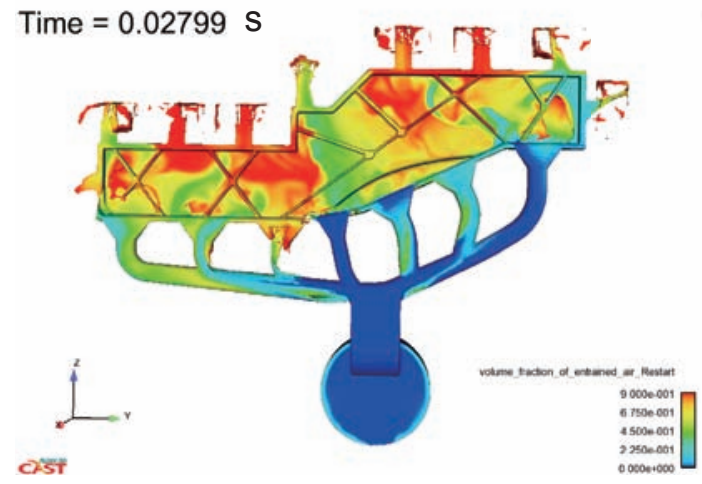

Time $=0.02020 \mathrm{~S}$

(b)

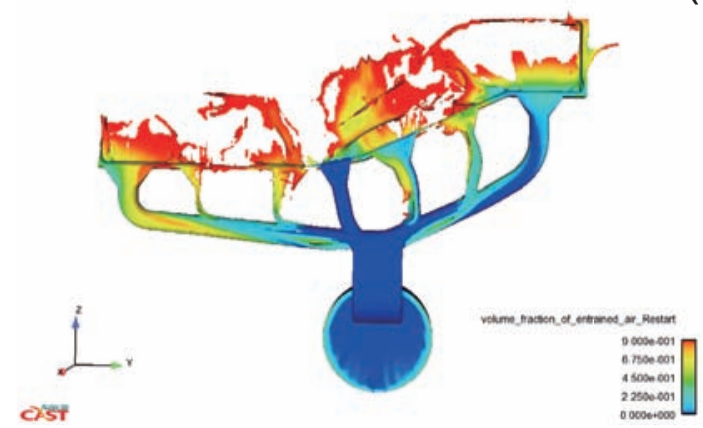

Time $=0.03638 \mathrm{~S}$

(d)

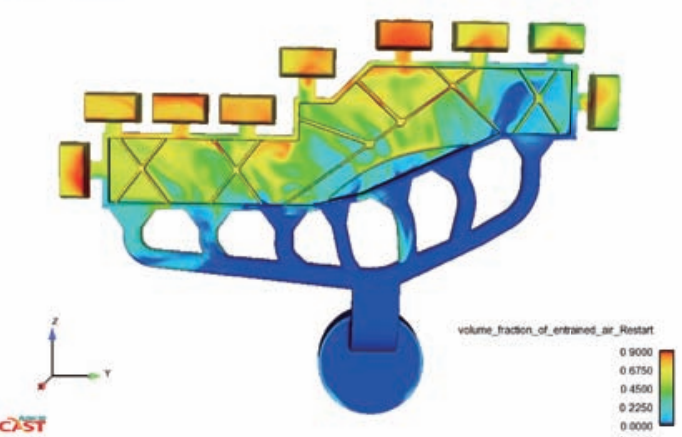

Fig. 5: Simulation results of filling process with initial gating system
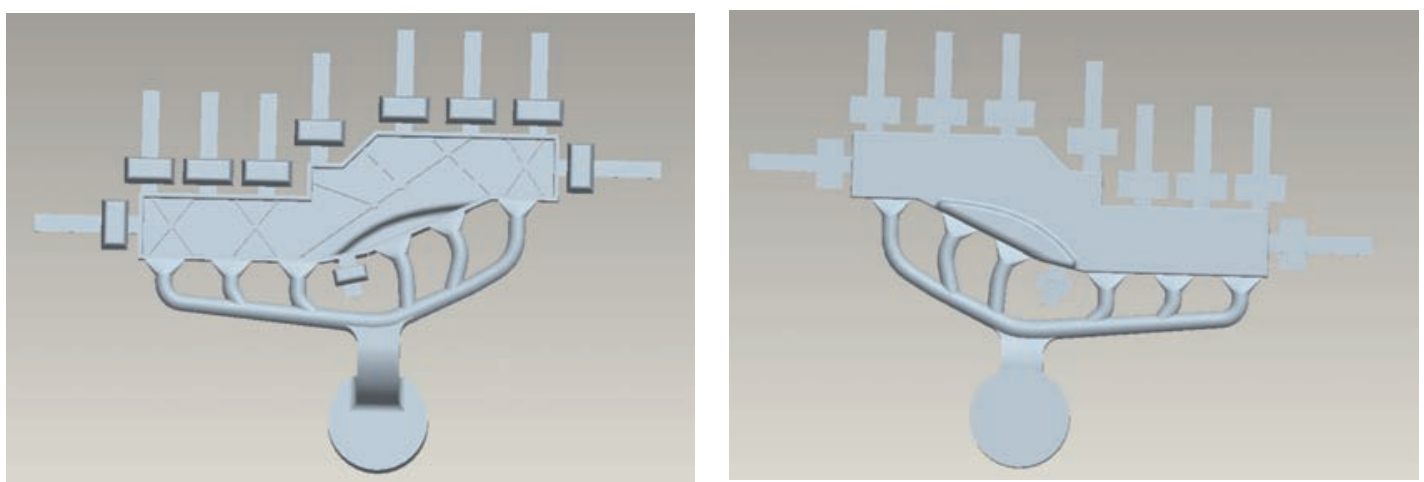

Fig. 6: 3D-Model of replacing middle ingate to overflow well made by Pro-E

system. In Fig. 7(a), the molten metal is filled from the left third ingate, and then to the mold cavity. Figure 7(b) shows a more stable filling state of molten metal in the optimized gating system than that in the initial gating system. With the optimized gating system, the gas has less involvement into the mold cavity, so the volume of air entrapment can be confined to a certain extent. When the filling time is $0.03 \mathrm{~s}$, the mold cavity is fully filled [Fig.7(c)]. Compared to the initial gating system, the confluence is decreased, and the filling time is slightly increased with the optimized gating system. The filling velocity is slower than that in the initial gating system because of the decrease of ingate number. However, the longitudinal load-bearing beam still has some confluence during filling, and some air entrapment defects are still observed [Fig. 7(d)], mainly in the top of the casting, and the filling sequence is not yet asynchronous. The third ingate is firstly fully filled during filling [Fig. 7(b)], which causes a new convection between this ingate and the middle overflow well, and the fluid filling from different ingates does not smoothly rise up. So, the gating system should be further optimized to remove the air entrapment defects in the top of the beam.

In order to make the filling liquid front more stable, to avoid the fluid flows preferentially into the middle overflow well, and to decrease the convection between the ingate and the middle overflow well, the middle overflow well is removed for further improvement. Figure 8 shows the final die design by removing the middle overflow well. Figure 9 is the simulated air entrapment distribution of the beam with final optimized gating system. It can be seen that the air entrapment defects are much fewer than that of the initial gating system. After the middle overflow well is removed from the gating system, the confluence is almost eliminated [Fig. 9(a)]. Figure 9(d) shows the simulated air entrapment distribution in the end of filling process with the final gating system after further optimization. The entrapped air is fully transferred into the overflow wells on 
(a)

Time $=0.01817 \mathrm{~s}$

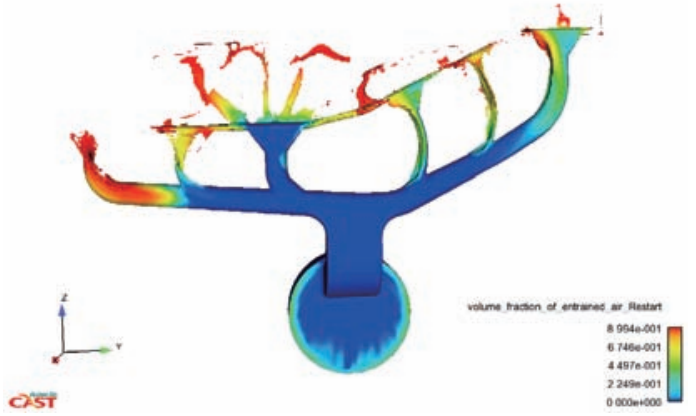

(c)

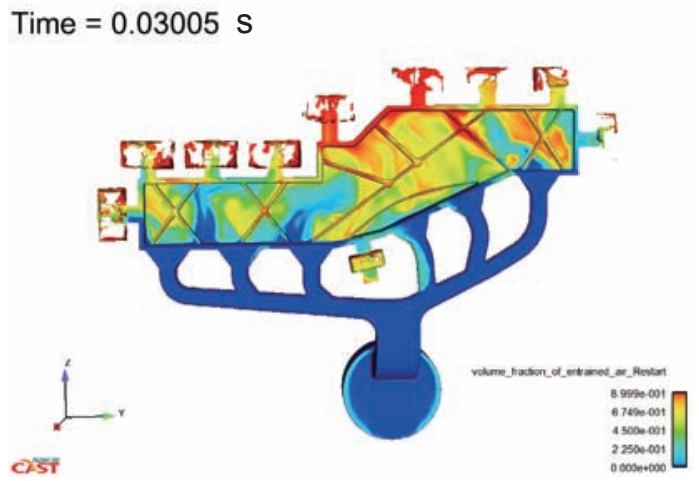

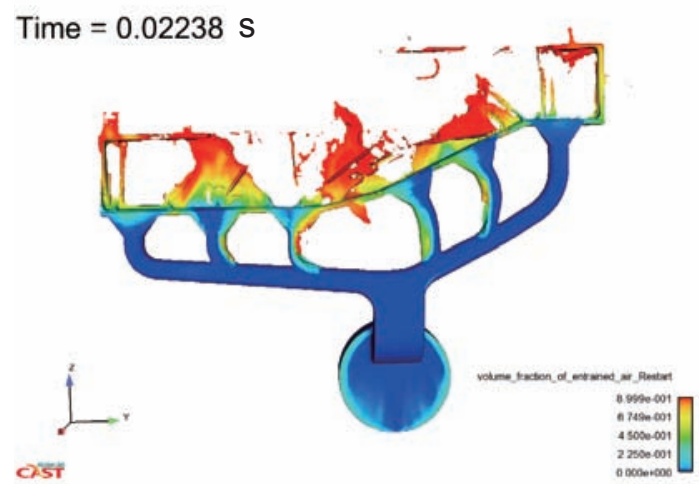

(b)

Time $=0.03636 \mathrm{~s}$

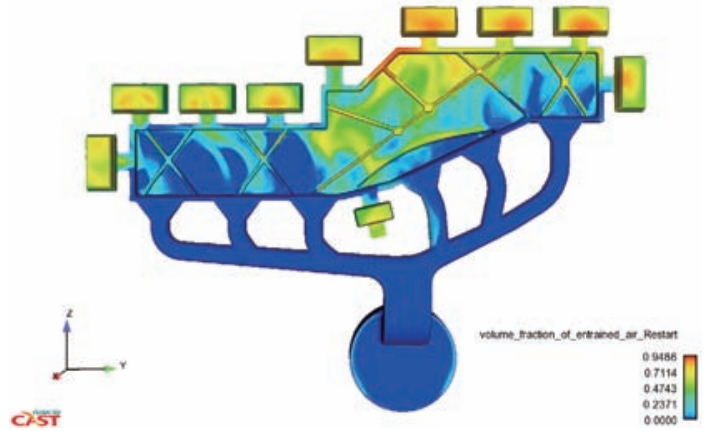

(d)

Fig. 7: Simulation results of filling processes with optimized gating system
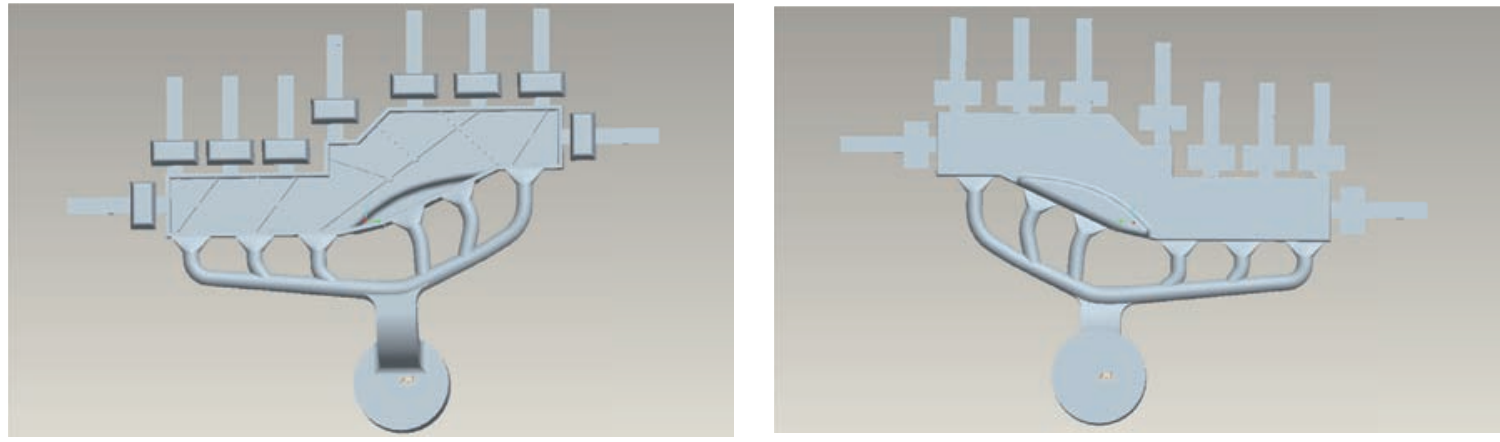

Fig. 8: 3D-Model of final gating system made by Pro-E

the top. The mold cavity does not show obvious air entrapment defects. Therefore, the final optimized gating system with the middle ingate removed almost eliminated the air entrapment defects in the mold cavity and distinctly improved the quality of the longitudinal load-bearing beam.

\section{Practical production verification}

Figure 10 shows the longitudinal load-bearing beam with glossy surface produced by the final optimized gating system. Figure 11 shows the metallographic photos at the critical area of the beam. There are no obvious air entrapments in the metallographic photos, of low or high magnification, and a dense microstructure is observed, which shows a high consistency with the simulation result.

Figure 12 is the X-ray test results of the critical area of the beam made by the final gating system. It shows no air entrapment existing in the critical area and the result is also consistent with the simulation result.

Mechanical properties test was performed according to DIN 50125 standard. Tensile test piece is a flat bar with original gauge length of $30 \mathrm{~mm}$, thickness of $3 \mathrm{~mm}$ and width of $8 \mathrm{~mm}$. Table 6 shows the mechanical properties of the longitudinal load-bearing beam under the final gating system. As it can be seen from Table $6, R_{\mathrm{m}}$ of the left sampling position is 203.9 $\mathrm{MPa}, R_{\mathrm{p} 0.2}$ is $157.4 \mathrm{MPa}$, the elongation $A$ is $2.4 \%$ and $R_{\mathrm{m}}$ of the right sampling position is $247.1 \mathrm{MPa}, R_{\mathrm{p} 0.2}$ is 165.1 $\mathrm{MPa}$, the elongation is $3.1 \%$. The tested results can meet the properties requirements of a longitudinal load-bearing beam.

According to Figs. 9-12 and Table 6, the practically produced thin-wall AlSi10MnMg longitudinal load-bearing beam has a good surface and internal quality. No obvious air entrapment defects are observed in the simulation result and in the metallographic photos of the final optimized longitudinal load-bearing beam. 
(a) Time $=0.01883 \mathrm{~s}$

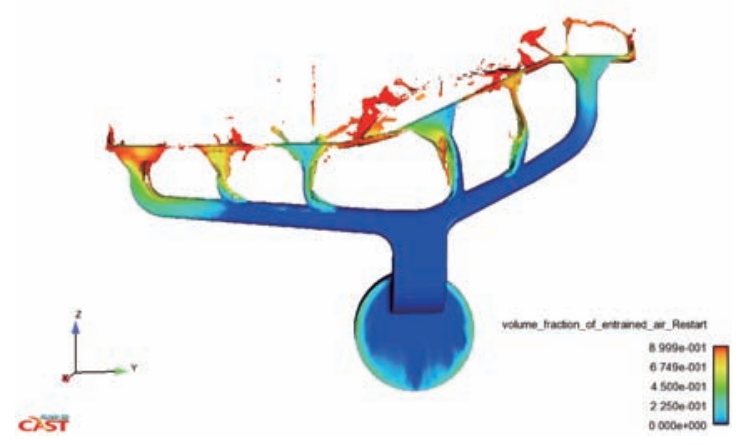

(c) Time $=0.02997 \mathrm{~s}$

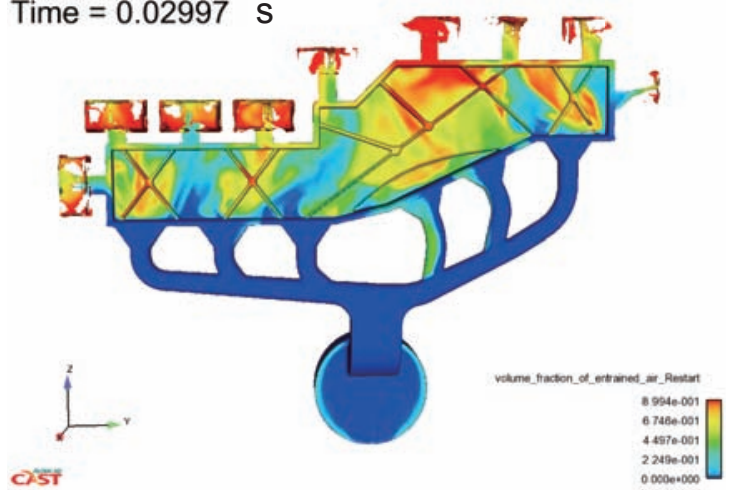

Time $=0.02204 \mathrm{~s}$

(b)
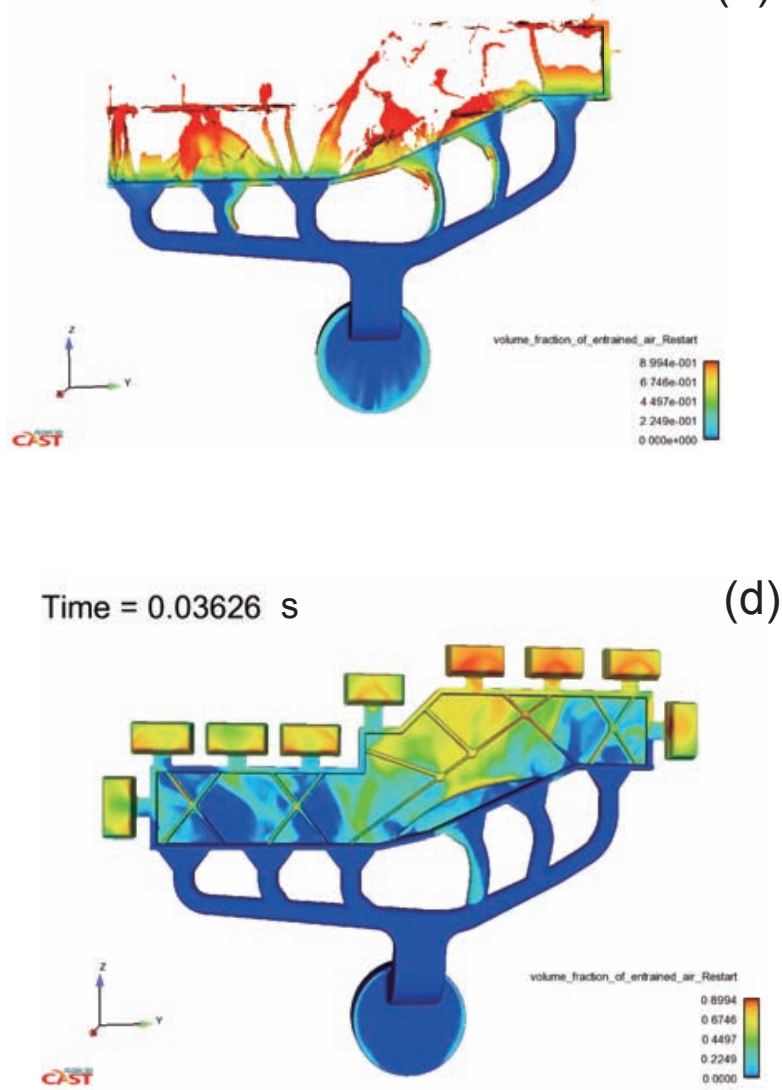

Fig. 9: Simulation results of filling processes with final optimized gating system
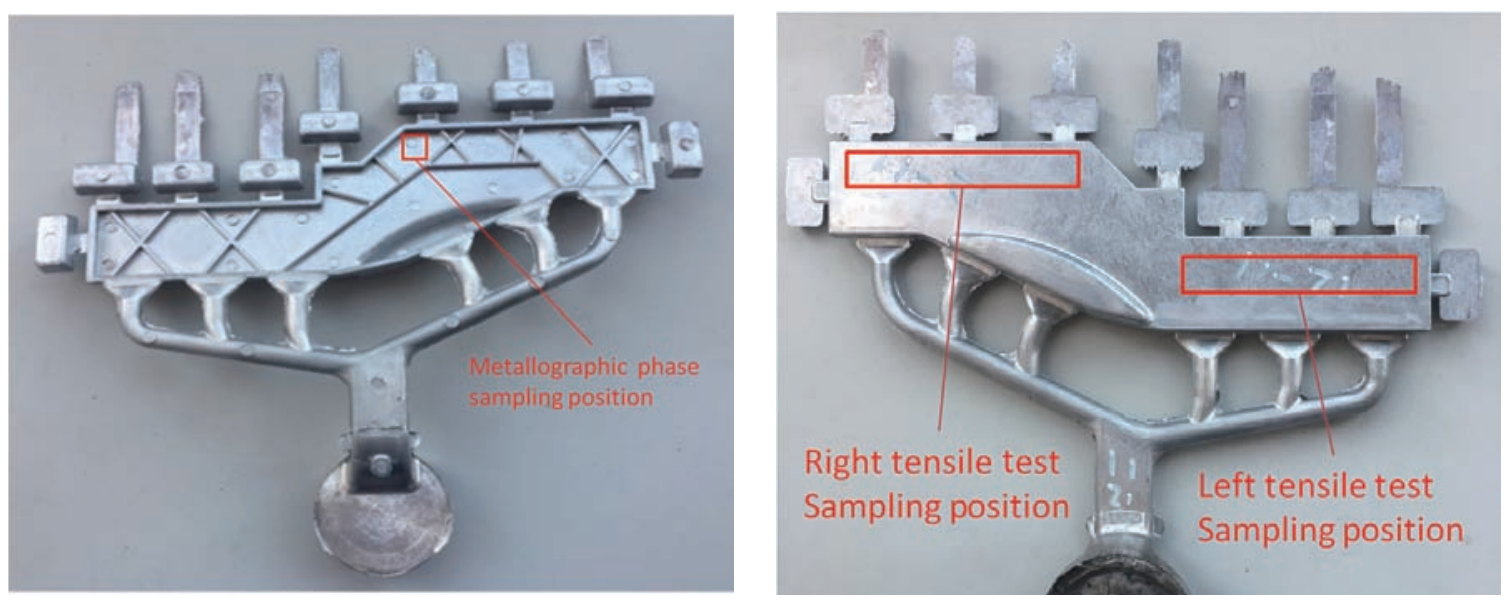

Fig. 10: Photos of produced parts with final optimizedgating system
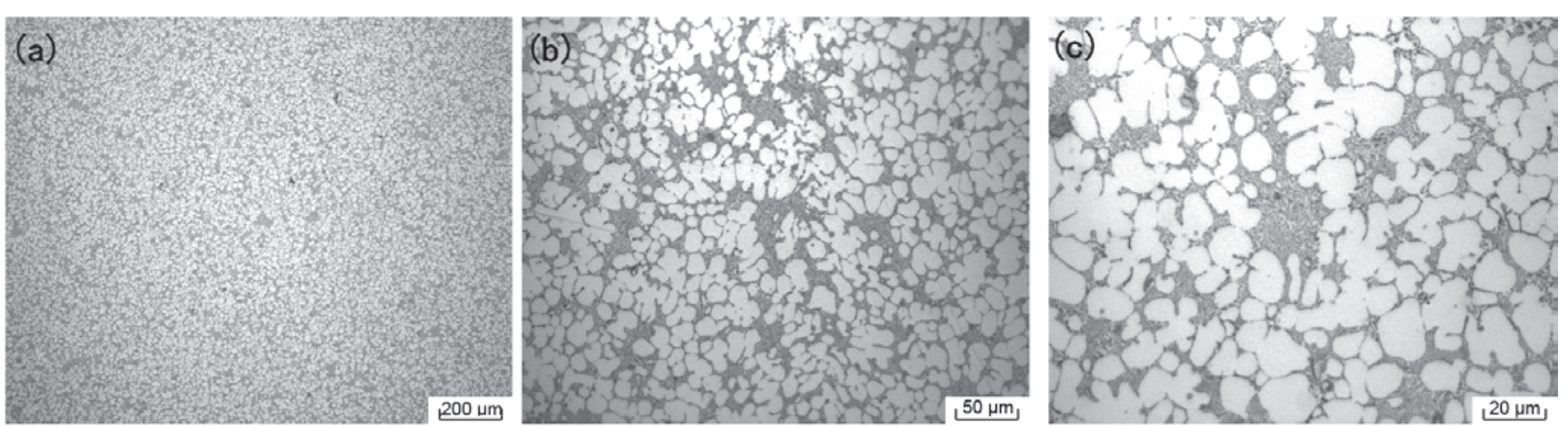

Fig. 11: Metallographic photos of final optimized longitudinal load-bearing beam from critical area 


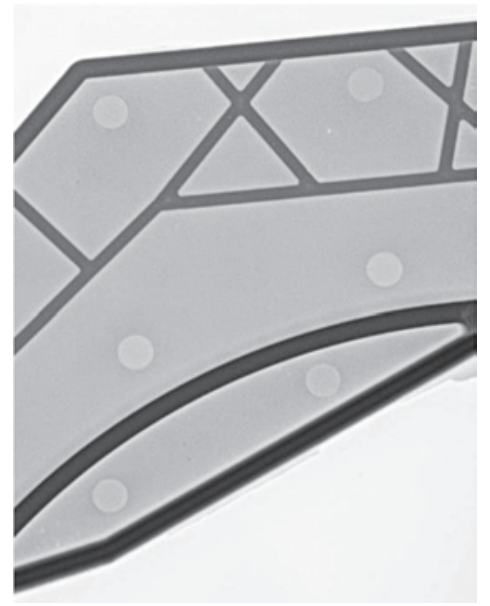

Fig. 12: X-ray test result of critical area based on final optimized gating system

Table 6: Mechanical properties of a longitudinal load-bearing beam produced by final optimized gating system

\begin{tabular}{cccc} 
& $\boldsymbol{R}_{\mathrm{p} 0.2}(\mathrm{MPa})$ & $\boldsymbol{R}_{\mathrm{m}}(\mathrm{MPa})$ & $\boldsymbol{A}(\%)$ \\
\hline $\begin{array}{c}\text { Properties } \\
\text { requirement }\end{array}$ & 145.0 & 185.0 & 2.0 \\
Left & 157.4 & 203.9 & 2.4 \\
Right & 165.1 & 247.1 & 3.1
\end{tabular}

\section{Conclusions}

The gating system of the HPDC thin-wall AlSi10MnMg longitudinal load-bearing beam is optimized. The filling process of the longitudinal load-bearing beam becomes obviously more stable and the volume of air entrapment has drastically decreased.

(1) When the beam is produced by the original designed gating system with a middle ingate, there exist obvious air entrapments in the critical area. Simulation results show that when the initial gating system contains a middle ingate, the filling of the molten metal is not stable, the middle ingate is firstly fully filled, and there is obvious confluence during the filling process. Air entrapment clearly exists in the mold cavity.
(2) After the gating system is optimized by replacing the middle ingate to an overflow well, the filling of molten metal becomes more stable. However, the confluence still exists. Air entrapment still appeared in the critical area of the longitudinal load-bearing beam. For further improvement, the middle ingate is removed. The fluid has much less confluence and the air entrapment defect is eliminated from the critical area with the final optimized gating system.

(3) The numerical simulation optimization is verified by practical production. The thin-wall HPDC AlSi10MnMg longitudinal load-bearing beam has a dense microstructure and less air entrapment by using the final optimized gating system. Mechanical properties can meet the application requirements of the beam.

\section{References}

[1] Shi Jianmin, Pries H, Stammen E, et al. Chemical pretreatment and adhesive bonding properties of high-pressure die cast aluminum alloy: AlSi10MnMg. International Journal of Adhesion and Adhesives, 2015, 61: 112-121

[2] Irfan M A, Schwam D, Karve A, et al. Porosity Reduction and Mechanical Properties Improvement in Die Cast Engine Blocks. Materials Science \& Engineering A, 2012, 535:108-114

[3] Alan A L, Anil K S, Bob R P. Advanced casting technologies for lightweight automotive applications. China Foundry, 2010, 7 (4): 463-469.

[4] Niklas A, Orden S, Bakedano A. Effect of solution heat treatment on gas porosity and mechanical properties in a die cast step test part manufactured with a new $\mathrm{AISi} 10 \mathrm{MnMg}(\mathrm{Fe})$ secondary alloy. Materials Science \& Engineering A, 2016, 667: 376-382

[5] Zhu Biwu, Li Luoxing, Liu Xiao, et al. Effect of Viscosity Measurement Method to Simulate High Pressure Die Casting of Thin-Wall AlSi10MnMg Alloy Castings. Journal of Materials Engineering and Performance, 2015, 24 (12): 5032-5036

[6] Jiang Wenming, Fan Zitian. Gating system optimization of low pressure casting A356 aluminum alloy intake manifold based on numerical simulation. China Foundry, 2014, 11 (2): 119-124.

[7] Zhang Yutuo, Li Guimao, Zhang Wanning. New filling system design for bolster casting and computer simulation. China Foundry, 2010, 7 (4): 349-351.

The work was supported by the Major Project of NSFC (51690161) and the Student Innovation Program Major Project of Northeastern University (ZD1708). 